CIC. Cuadernos de Información y Comunicación

ISSN: 1135-7991

\title{
Prácticas fotográficas contemporáneas en la cultura digital: Hacia un giro performativo
}

\author{
Gloria Jiménez López ${ }^{1}$
}

Recibido: 15 de mayo de 2019 / Aceptado: 29 de mayo de 2019

Resumen. A lo largo de este artículo se revisará la noción de performatividad aplicada al entorno de la comunicación visual contemporánea. La performatividad se propone como un posible paradigma de análisis de las imágenes que circulan en las redes sociales que puede posibilitar una mayor comprensión de las interacciones y de las prácticas fotográficas contemporáneas de la cultura digital.

Palabras clave: Fotografía, performatividad, prácticas sociales, comunicación, cultura visual.

[en] Contemporary Photographic Practices in Digital Culture: towards a Performative Paradigm

\begin{abstract}
Throughout this article, the notion of performativity applied to the contemporary visual communication environment will be reviewed. Performativity is proposed as a possible paradigm of analysis of the images circulating in social networks that can enable a greater understanding of the
\end{abstract} interactions and contemporary photographic practices of digital culture.

Keywords: Photography, Performativity, Social practices, Communication, Visual culture.

Sumario. 1. El giro performativo. 2. Tras la pos. 3. Imagen-acto y cultura digital. 4. Compartir lo íntimo. 5. Conclusiones. 6. Referencias bibliográficas.

Cómo citar: Jiménez López, G. (2019). Prácticas fotográficas contemporáneas en la cultura digital: Hacia un giro performativo. Cuadernos de Información y Comunicación, 175-186.

\section{El giro performativo}

Desde la llegada y afianzamiento en los últimos años de redes sociales que ponen especial atención en lo visual, la comunicación online a través de fotografías se ha convertido en un fenómeno de especial interés por parte de investigadores de distintas disciplinas.

Estos entornos señalan hacia un campo de investigación novedoso, que tiende a suscitar actitud crítica entre analistas e investigadores, dado el desafío que suponen estas formas comunicativas para clásicas nociones como autenticidad o intimidad. La comunicación online parece venir cargada de una exhibición del entorno privado

$1 \quad$ Universidad Complutense de Madrid 
sin límites, sumado a un despliegue de yoísmo materializado en tipología de imagen: el selfie.

Los cambios tecnológicos en el entorno de la imagen siempre han suscitado cierta controversia. Sin ir más lejos, la llegada de las tecnologías digitales fue vivida como una "muerte de la fotografía" (Green y Lowry, 2007) para quienes veían en la inmaterialidad del píxel peligrar el estatuto de veracidad que el devenir histórico y teórico le había designado.

La cuestión deontológica de las posibilidades de mostrar lo real es la piedra angular de los debates dentro del universo de lo fotográfico. Debates que toman fuerza en la actualidad, en un momento en que en las redes sociales abundan imágenes autobiográficas cuya autenticidad parece cuestionable. De alguna manera, las discusiones en torno a la fotografía tienden a pivotar en torno a los límites entre la ficción y la realidad, siendo esta la principal cuestión a dilucidar.

Pero hay otras formas de mirar las imágenes. Existen corrientes teóricas que abrazan abordajes desde otros lugares y que apelan, en definitiva, a la necesidad de teorías no esencialistas de las condiciones de realismo fotográfico que evidencien el falso binomio realidad-ficción (Ribalta, 2018). Necesitamos nuevos paradigmas para entender las imágenes en un mundo que tiende a la complejidad.

La mayoría de los escritos canónicos sobre fotografía parten de paradigmas semióticos de la imagen que entienden la fotografía desde la idea de texto. Pese a que este enfoque es el más extendido, su aplicación en los entornos comunicativos que señalamos resulta problemática. Las imágenes, entendidas como práctica social, trascienden lo textual y operan como dispositivos más que como signos.

Las fotografías en este entorno son el resultado de prácticas cotidianas, no necesariamente discursivas, en las que interactúan diversos agentes y que además, intervienen en la construcción de sentido. Por tanto, son materiales que poseen un poder transformador y reclaman su fuerza más que su significado (Fernández, 2012).

\section{Tras la pose}

"Cuando me siento observado por el objetivo, todo cambia: me constituyo en el acto de "posar", me fabrico instantáneamente otro cuerpo, me transformo por adelantado en imagen" (Barthes, 1989, p. 41).

Según argumenta Mieke Bal, "no conviene tratar por separado la performance (en su sentido anglosajón de actuar) y la performatividad (que una palabra haga lo que dice)" (Fernández, 2012, p. 1).

Performance y performatividad son nociones difícilmente separables que, además, se encuentran en la matriz de lo fotográfico: una fotografía no deja de ser un diálogo o negociación entre el autor y la escena capturada, al tiempo que toda imagen entraña cierta performance en tanto que el acto de la imagen interviene en la escena modificándola inevitablemente. De alguna manera, las cosas no suceden de la misma forma si hay una cámara delante.

La fotografía no puede desligarse de la pose, ni tampoco del posicionamiento del fotógrafo que toma la imagen. Por lo tanto, entender la fotografía como un signo indicial no deja de ser desafiante. 
En 1838, Louis Daguerre, mediante su procedimiento fotográfico el daguerrotipo, consiguió lo que se considera el primer retrato de la historia de la fotografía, la primera imagen fotografía en la que aparece una figura humana. En su imagen del Boulevard du Temple, podemos observar cómo en la esquina inferior izquierda aparece la figura de un limpiabotas. Fontcuberta (2002), sobre el daguerrotipo:

La imagen del espejo es fugaz y el reflejo no queda retenido. La fotografía, en cambio, ese "espejo con memoria", según se llamaba el daguerrotipo (esta expresión fue propuesta por Oliver Wendell Holmes en 1861), inmoviliza nuestra imagen para siempre, con todo lujo de detalles y la verdad como pátina. (p. 30)

El invento del daguerrotipo es propio de la Modernidad: época de grandes expediciones y descubrimientos, de desarrollo de la cultura tecnocientífica y de las ciudades. El París del daguerrotipo era de gran efervescencia urbana, en un momento en el que se estaban construyendo las grandes avenidas y bulevares. Y Daguerre, con su fotografía, quería capturar precisamente eso. Sin embargo, debido a los largos tiempos de exposición que demandaba el procedimiento (alrededor de veinte minutos), resultaba inviable capturar a los viandantes y carruajes que estaban en continuo movimiento. A pesar de todo, llama la atención la figura estática y definida del limpiabotas.

Y es que, como afirma la historiadora y profesora Shelley Rice (Fontcuberta, 2016), el limpiabotas que aparece en la fotografia no era tal, sino un actor o el propios asistente de Daguerre siguiendo sus instrucciones.

Figura 1. Dedicatoria final de los Erotemata.

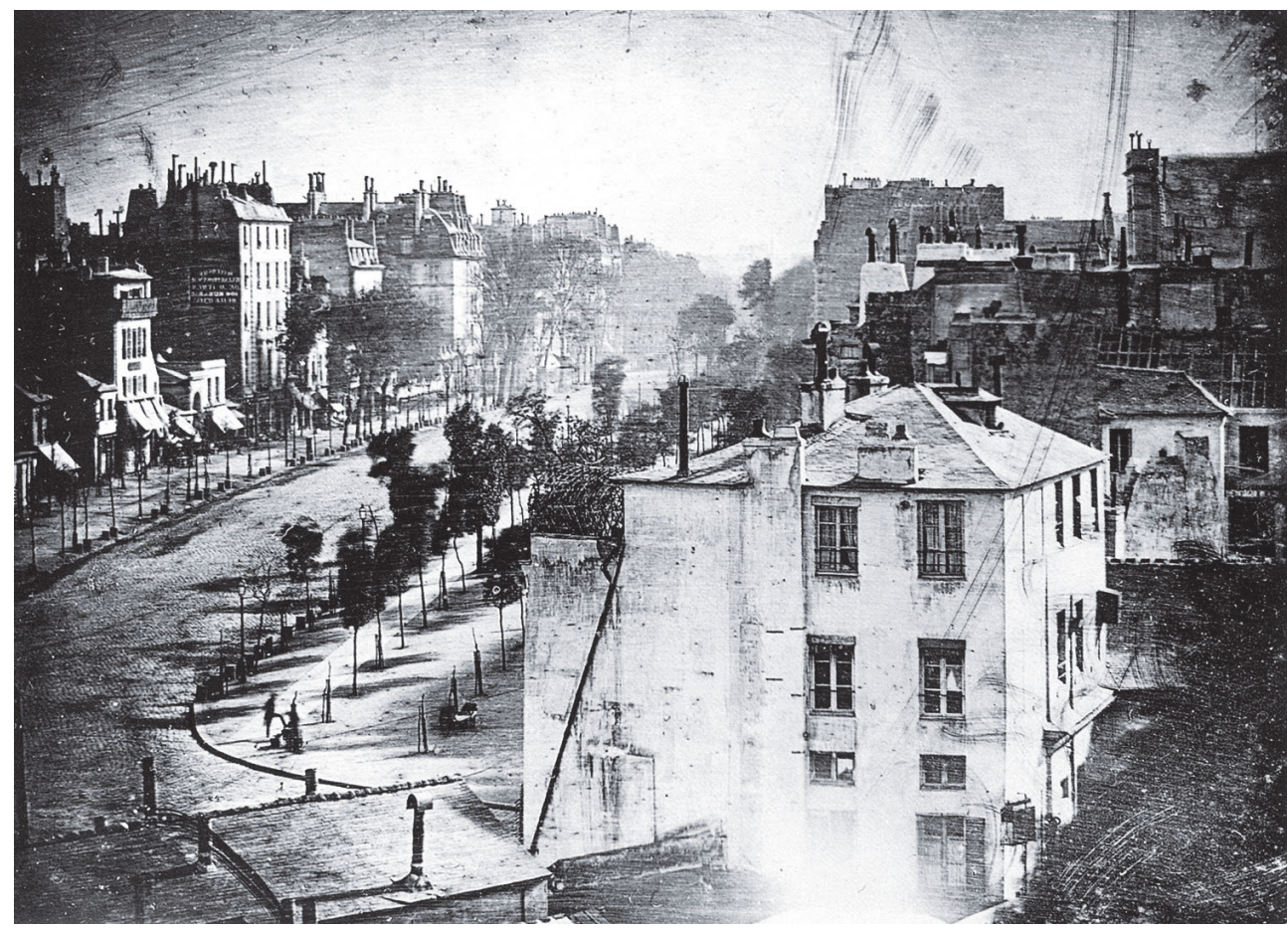

Fuente: Biblioteca Histórica UCM. 
Gracias a la figura del limpiabotas, la fotografía tiene vida y una escala humana que permite valorar la grandiosidad de la avenida parisina. Pero no hemos de olvidar que el primer retrato de la historia de la fotografía también es la primera performance fotográfica.

La limitación técnica del procedimiento hizo que el considerado padre de la fotografía, Daguerre, comprendiera aquello a lo que Walter Benjamin (1989) se refería cuando decía que la naturaleza que le habla a la cámara es distinta de la que habla a los ojos. El propio Daguerre, a través de su performance, cuestionó el binomio fotografía-realidad, señalando de alguna manera, hacia el hecho de que lo que se muestra a través de la lente parece estar conformado por un régimen de verdad único: "el uso estrictamente documental de la cámara fracasa en su intento por captar la realidad viva; es sólo engañando como podemos alcanzar una cierta verdad, es sólo con una simulación consciente como nos acercamos a una representación epistemológicamente satisfactoria" (Fontcuberta, 2016, p. 107).

Esta contradicción constitutiva de la fotografía viene a señalar lo que entendemos por las dos particularidades del signo fotográfico:

- La fotografía es al mismo tiempo huella y gesto: Una fotografía es el resultado de capturar lo que se encuentra delante del visor, pero apunta antes que todo, al propio acto de fotografiar. Peirce señala que "el signo indicial guarda menos relación con sus orígenes casuales que con el modo de aludir al hecho de su propia inscripción" (Green y Lowry, 2007, p. 50).

- La fotografía contiene varios presentes: El presente de la creación de la imagen, que constituye un aquí y ahora que no se puede traducir a un lenguaje y pertenece al orden de la experiencia (Fischer, 2011). Y por otro lado, el presente del visionado, el momento en el que el visionador da sentido a la imagen. Ambas temporalidades, "el aquí-ahora” y el "allí-entonces" (Green y Lowry, 2007, p. 60), pertenecen a distintos regímenes de verdad.

La fotografían de "El ahogado" (Hippolyte Bayard, 1840) es otro ejemplo del fenómeno de la performatividad en los inicios de la fotografía. Se trata de un autorretrato del propio autor, Bayard, en lo que parece la escena de un suicidio, que además que iba acompañada de una nota ${ }^{2}$ firmada con las siglas H.B, en la que se comentan las razones del trágico acontecimiento.

Esta imagen es significativa por su dimensión performativa e histórica.

Bayard no fue únicamente un pionero de la fotografía, también inventó su propio procedimiento fotográfico, el "dibujo fotogénico" hacia 1837. A pesar de que este

\footnotetext{
2 "Este cadáver que ven ustedes es el del señor Bayard, inventor del procedimiento que acaban ustedes de presenciar, o cuyos maravillosos resultados pronto presenciarán.

Según mis conocimientos, este ingenioso e infatigable investigador ha trabajado durante unos tres años para perfeccionar su invención.

La academia, el Rey y todos aquellos que han visto sus imágenes, que él mismo consideraba imperfectas, las han admirado como ustedes lo hacen en este momento.

Esto le ha supuesto un gran honor, pero no le rendido un céntimo. El gobierno que dio demasiado al señor Daguerre, declaró que nada podía hacer por señor Bayard y el desdichado decidió ahogarse. ¡Oh veleidad de los asuntos humanos! Artistas, académicos y periodistas le prestaron atención durante mucho tiempo, pero ahora permanecen la morgue desde hace varios días y nadie le ha reconocido ni reclamado. Damas y caballeros, mejor será que pasen ustedes de largo por temor a ofender su sentido del olfato, pues, como pueden observar, el rostro y las manos de caballero comienza descomponerse" H.B 18 de octubre de 1840" Zorita, M. (2013).
} 
Figura 2: Hippolyte Bayard (1840): El Ahogado (“Le Noyé”)

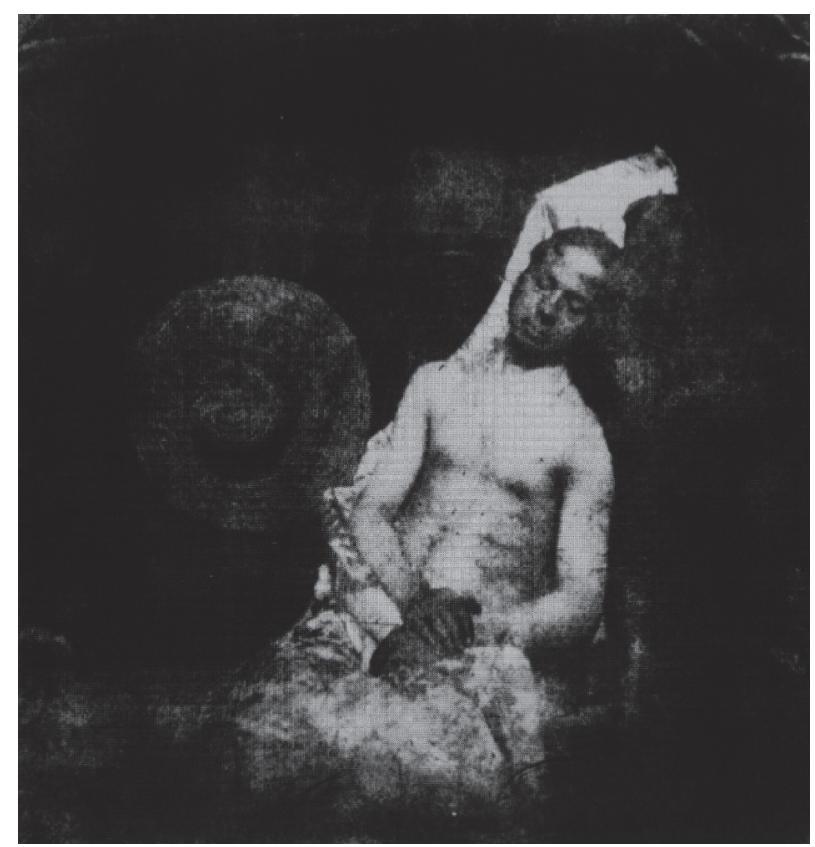

procedimiento existía dos años antes del daguerrotipo, no obtuvo ningún tipo de reconocimiento por él, al contrario que Daguerre. Bayard, en respuesta a esta ausencia de reconocimiento, difundió esta fotografía en la que el propio autor posaba ahorcado y firmaba la nota del reverso de la imagen.

Esta imagen no es solamente el resultado de una performance, también es performativa: su circulación hizo que finalmente el gobierno lo contratara para trabajar como fotógrafo, obteniendo parte del reconocimiento que le debía.

Las fotografías no siempre resultan satisfactorias epistemológicamente, pero este hecho no tiene por qué restar valor a las imágenes. Ejemplos como los anteriormente citados dan cuenta de que la fotografía es un artefacto cuyos usos responden a diversas intenciones, algunas de los cuales superan el valor documental y factual. La performatividad, lejos de conformar un obstáculo epistemológico, puede abrir vías hacia la emancipación. Más allá de su capacidad de mostración, las fotografías poseen capacidad de actuación.

\section{Imagen-acto y cultura digital}

A pesar de que la cuestión indicial es problematizada desde la propia génesis del medio, comienza a ser especialmente controvertida con la llegada de la fotografía digital y las posibilidades manipulativas que entraña:

Los píxeles que proporcionan la textura de la imagen electrónica funcionan estructuralmente como las pinceladas para el pintor: constituyen unidades de configuración sobre 
las que podemos operar particularmente. Me gusta en este sentido insistir en que la fotografía analógica se inscribe y la fotografía digital se escribe. Inscripción y escritura señalan dos estadios de competencia epistemológica entre los que se debate la creación contemporánea: de la descripción al relato. Por eso en la fotografía actual se acusa una crisis del documentalismo y una tendencia a la narración y lo discursivo. Siempre se ha dicho que la fotografía era "escritura con luz", pero cada vez más esa afirmación se aparta de lo metafórico para cumplirse literalmente. (Fontcuberta, 2016, p. 187)

Esta problematización de la ontología de la imagen ha interpuesto inevitablemente una distancia simbólica entre las nociones de fotografía y realidad, de modo que las prácticas se han visto alteradas: la fotografía ya no es una tecnología de la memoria, sino una tecnología del yo (Foucault, 2008).

En la contemporánea era de la comunicación mediada, la cámara opera como un artefacto de uso cotidiano, como una prolongación del yo que el individuo usa para proyectar su subjetividad. Este fenómeno es especialmente visible en las redes sociales, entornos en los que las imágenes fotográficas tienden a ser usadas como forma de inscripción autobiográfica, como una suerte comunicación interpersonal -e intrapersonal- basada en la propia identidad, que inevitablemente ha reconfigurado nuestra percepción a cerca de los límites entre lo público y lo privado.

Este giro copernicano hacia el yo es especialmente notable en Instagram, una plataforma en la que abundan imágenes de lo cotidiano, escenas prosaicas y autobiográficas que chocan con las nociones tradicionales de privacidad, y por tanto suelen ser leídas como una expresión del individualismo, narcisismo y vanidad de la sociedad contemporánea.

\section{Compartir lo íntimo}

La generalización de este tipo de prácticas fotográficas invita a repensar este fenómeno en una nueva clave. En este sentido, Fontcuberta (2016b) insiste en que

Transmitir y compartir fotos funciona así como un nuevo sistema de comunicación social, como un ritual de comportamiento que queda igualmente sujeto a particulares normas de etiqueta y cortesía. Entre estas normas, la primera establece que el flujo de imágenes es un indicador de la energía vital, lo cual nos devuelve al inicial argumento ontológico de fotografío, luego existo. La mirada de Dios, es decir: la mirada de Zeus, es decir: la mirada de Zeiss, es decir: la mirada de la cámara, devienen hoy un soplo de vida. (p. 31)

La integración de las cámaras fotográficas en la telefonía móvil ha acortado enormemente la distancia temporal entre la toma de la imagen y su puesta en circulación. Este dinámico modo de proceder pareciera estimular la captura compulsiva de imágenes, razón por la cual vivimos en una sobreabundancia de imágenes que ha dado lugar sociedad escópica, en la que paradójicamente dedicamos más tiempo a producir y compartir imágenes que a visualizarlas. La era del Homo Photographicus, en la que producción y consumo de imágenes acontecen con naturalidad. (Fontcuberta, 2016b).

El Homo Photographicus vive a través de las imágenes y usa la fotografía como un medio de comunicación. Es por ello que capturar imágenes y compartirlas instan- 
táneamente ha anulado la idea de "lo fotografiable", del "momento Kodak" como un momento especial para la captura, produciéndose una mundanización de la práctica fotográfica (Prada, 2018), que explicaría la progresiva intromisión de la lente en espacios que en otros tiempos se consideraban privados.

La intimidad posee una enorme potencia comunicativa. Al compartir imágenes de lo íntimo y de la vida cotidiana, los usuarios se nutren de una sensibilidad sutil e intersubjetiva. Las imágenes sirven como soporte visual para compartir sensaciones, formas de ser y estar en el mundo, conformando prácticas que permiten a los usuarios encontrar subjetividades afines, y por tanto, crear comunidad.

Comunidades en las que Prada (2018) valora una potencia para promover formas alternativas de experimentar la vida, de flexibilizar los parámetros normativos, y que dan cuenta de la irreductibilidad del análisis de las imágenes fotográficas a meros significados textuales.

En la plataforma Instagram podemos encontrar muchos ejemplos de comunidades virtuales que promueven novedosos universos de sentido y formas de vida alternativas. A través de hastags como \#empoweredbithproject, se pueden hallar perfiles como@australianbirthstories (Figura 3).

Figura 3. Perfil en Instagram de @australianbirthstories.

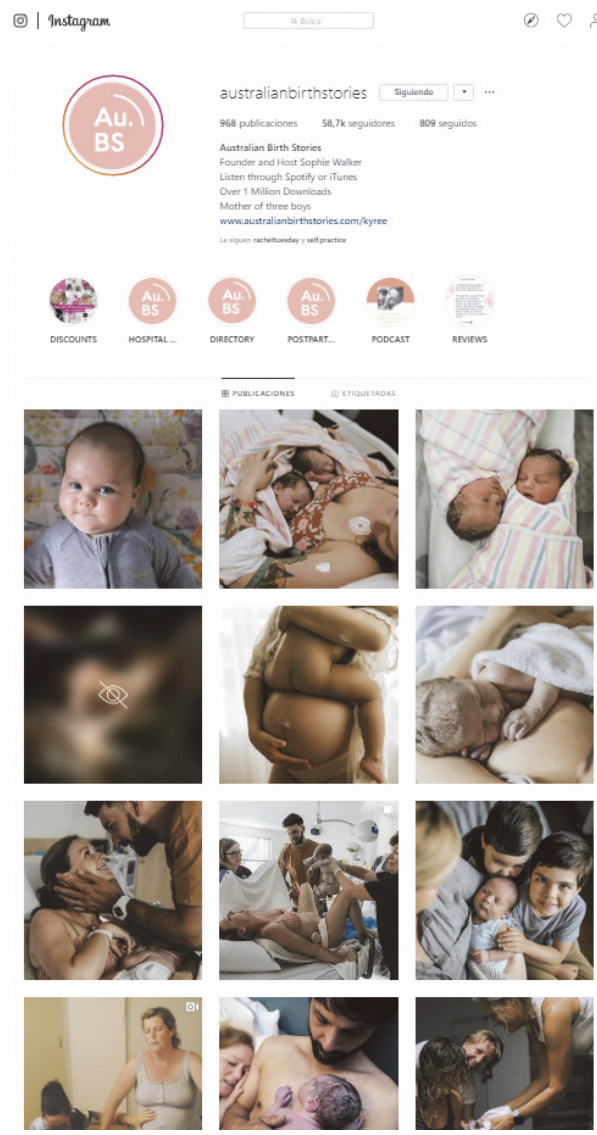

Fuente: 
Este perfil de Instagram hace un llamamiento a las madres de la plataforma para mostrar fotografías de la maternidad con una crudeza sin precedentes, contribuyendo a la visibilización de una realidad que no tenía espacio en el mundo de la imagen en circulación- y que, de hecho, en ocasiones no pasan los filtros de sensibilidad que la red impone, como se puede apreciar en la imagen borrosa de la primera columna del feed. Además de visibilizar esta realidad, en estos espacios virtuales también se dan llamadas a la acción e interacciones materiales, como en el ejemplo de la usuaria @ racheltuesday, quien a través de un llamamiento en su perfil, consiguió doce litros de leche donada de otras madres de la plataforma.

Otro ejemplo de comunidad es el del movimiento \#vanlife, en el que podemos encontrar algunos perfiles como@nomadic_van_(Figura 4). \#Vanlife es un movimiento social que ha eclosionado en Instagram. Una fuente de inspiración para individuos y familias que deciden emprender un estilo de vida nómada, convirtiendo sus furgonetas en hogar. Este movimiento tiene que ver con valores contemporáneos populares en las redes como el del minimalismo o nomadismo digital. Estas comunidades muestran en sus imágenes su modo de vida, compartiendo su realidad, pero también reflexiones y consejos para poder llevarlo a cabo.

Figura 4. Perfil en Instagram de @nomadic_van_.

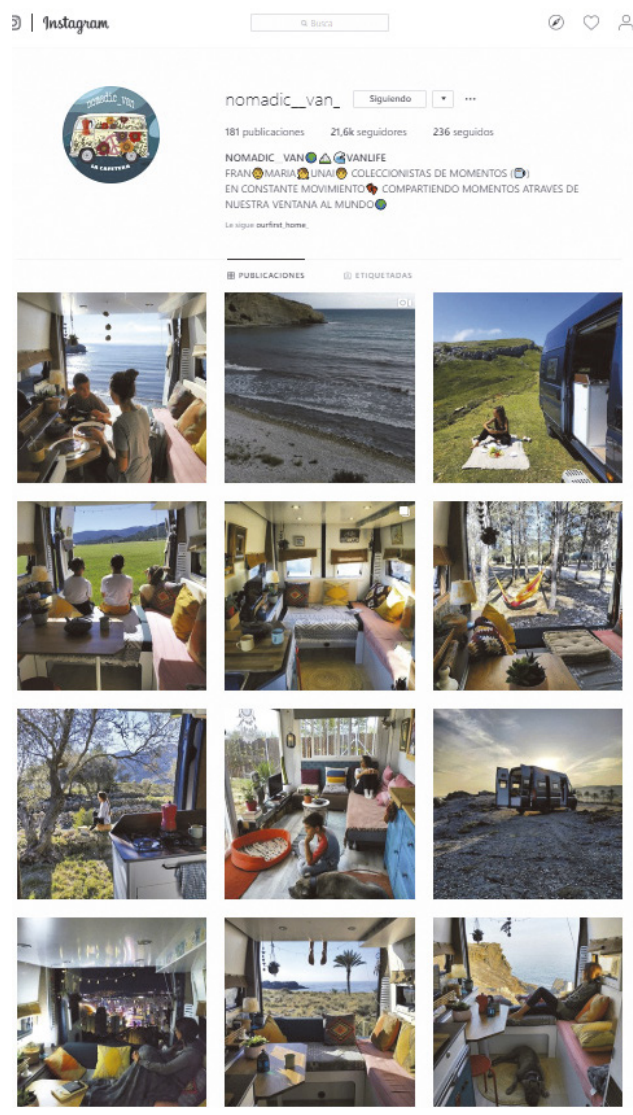

Fuente: 
Cuando Austin, en 1955, define la performatividad como la capacidad de acción de los enunciados, impulsa la apertura de todo un paradigma. El filósofo del lenguaje había observado que hay palabras que implican, forzosamente, acciones.

Esta dimensión performativa de la comunicación tiene su equivalencia en lo que llamamos imágenes-acto o actos de imagen: imágenes que interpelan a los espectadores, que permiten tomar conciencia, comprendiendo que "más allá de los significados ideológicos (...) en tanto que construcción social, la fotografía posee la capacidad de afectarnos desde su atractivo, cualidad estética y poética en el presente efímero" (Barrios, 2014, p. 2).

Esta dimensión de imagen-acto de la fotografía es clave para entender las interacciones que se están produciendo en Instagram. La fuerza visual de las imágenes fotográficas facilita que estas comunidades afectivas y estéticas promuevan imaginarios y estilos de vida que tienen un impacto en el mundo material.

Posteriormente a la teoría de Austin, Judith Butler (2017) en su reflexión en torno al género, formula la teoría de la performatividad, señalando hacia el hecho de que el género es una cuestión cultural y por tanto no esencialista, que se crea mediante el propio acto del habla de dar una identidad de género a un individuo y se recrea en el día a día a través de la adherencia a ciertos símbolos.

Lo performativo, por tanto, es un acto de deconstrucción que se sustenta en esencia en la idea de acción y agencia. Las imágenes, desde este marco, son formas de ser, hacer y de estar, prácticas políticas y simbólicas.

Internet se presenta como un espacio de fisura y "biopoder" (Foucault, 2006) en lo relativo, por ejemplo, a las lógicas binarias del género. El entorno online dota de agencia al individuo para cuestionar las dicotomías normativas debido a que la identificación subjetiva de la persona no está condicionada por su corporalidad. Se podría decir, en este sentido, que redes sociales y la comunicación online funcionan aquí como una "tecnología del género" (de Lauretis, 1989).

Si usamos el hashtag \#genderfluid, encontraremos perfiles como el de @marcopintus.makeup. (Figura 5). Este perfil es un ejemplo de agencia, de empoderamiento y de cómo través de un feed estéticamente cuidado, se puede llegar a una gran audiencia e interpelar a una comunidad global de sentires no normativos, en aras de una aceptación personal y social, normalización y emancipación.

Estas comunidades son importantes en buena medida por su capacidad de alcanzar audiencias globales y penetrar en los universos simbólicos de los individuos de una forma que la comunicación, a escalas grupales y masivas no consigue. Las narrativas autobiográficas potencian la sensación humanidad, a pesar de que el entorno online haga que las interacciones puedan parecer a priori un tanto desencarnadas. Sin embargo, es esta sensación de humanismo lo que crea un efecto de empatía que permite la apertura de espacios de resistencia respecto a la normatividad.

Un ejemplo de práctica de resistencia visual sería el perfil de @celestebarber (figura 6), una actriz que comparte imágenes imitando las poses de las modelos que estamos habituados a ver en los medios, y que no dejan de ser una reproducción de estereotipos de género basados fundamentalmente en la fetichización y la cosificación de la mujer. 
Figura 5: Perfil en Instagram de @marcopintus.makeup.

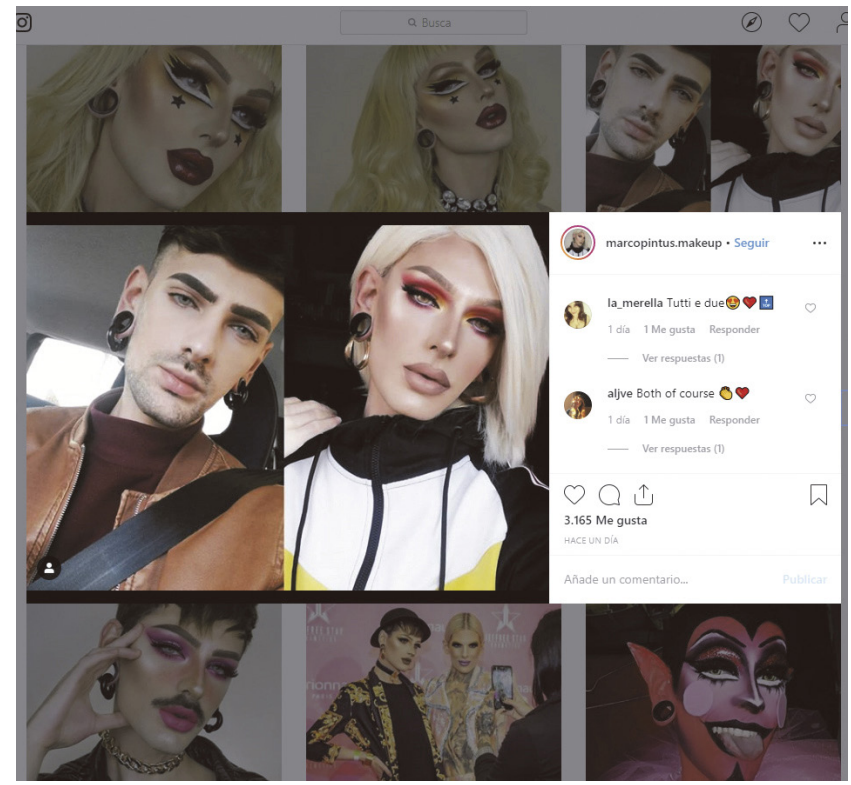

Figura 6: Perfil en Instagram de @ celestebarber.

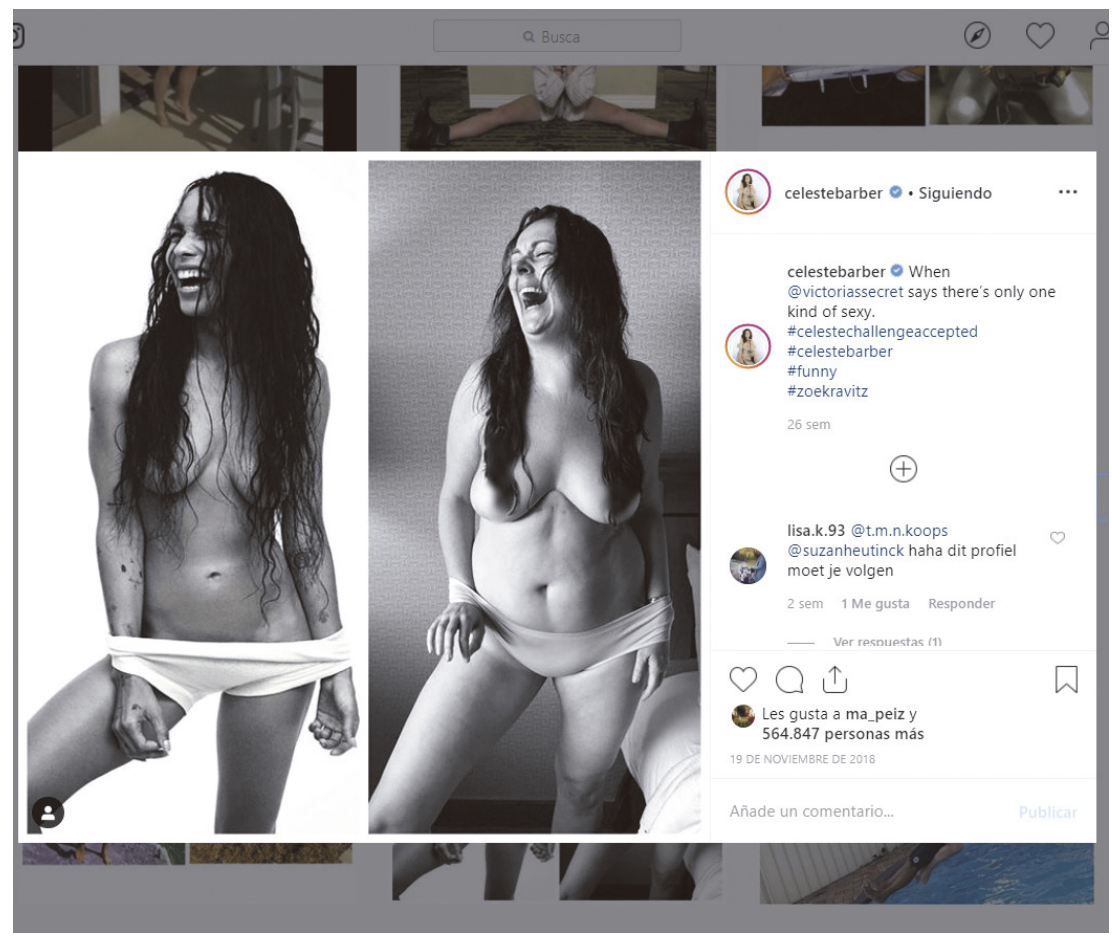




\section{Conclusiones}

El camino recorrido hasta aquí nos ha permitido ampliar la mirada hacia las prácticas fotográficas contemporáneas, y entenderlas a la luz de la performatividad, como algo más que un simple reflejo del narcisismo.

Quizás sea por la economía verbal de lo fotográfico, un medio que conforma una forma de comunicación esencialmente experiencial y visual, que resulta un vehículo idóneo para para entablar lazos de relación y sensación de comunidad.

La performatividad, se presenta como un paradigma a través del cual de recuperar la capacidad heurística de las fotografías, ayudándonos a pensar, poniéndose el acento en lo que las imágenes producen y lo que nosotros hacemos con ellas al ponerlas en circulación (Fernández, 2012). Esta mirada responde a transformaciones socioculturales que se han ido dando en los últimos años y puede dotarnos de explicaciones frente a los desplazamientos que se han ido dando, por ejemplo, en lo relativo a las prácticas fotográficas (superando la noción tecnología de la memoria para devenir tecnología del yo o tecnología de género).

Lo performativo implica presencia, corporalidad, y por tanto no se puede desligar de lo autobiográfico. Es por ello que producir fotografias en este sentido tiene una dimensión auto-reflexiva, pues en su matriz enunciativa está la descripción de las condiciones de producción de la imagen y el posicionamiento del autor. De modo que constituye un agenciamiento en lo relativo a la libertad de lo que se muestra, teniendo en cuenta que cada imagen que se sube a la red es un acto, en el sentido de Austin, que produce realidades. La doble dimensión de lo indicial (huella-gesto) abre un espacio de autoafirmación, en tanto que las imágenes son emanación y cuestionamiento de lo real; y el realismo, más que una verdad ontológica, una cuestión estética.

Los estudios visuales han ido tomando importancia conforme se ha ido entendido que las imágenes son un modo de conocimiento, pero que también conforman formas de hacer y de estar. La tendencia en las prácticas contemporáneas da cuenta de la demanda de enfoques holísticos, que entiendan la comunicación como un entramado complejo y que supone un reto para el investigador que ha de revisitar no únicamente los espacios de interacción, sino el lugar desde el cual se observan.

\section{Referencias bibliográficas}

Austin, J., \& Urmson, J. (1998): Cómo hacer cosas con palabras: Palabras y acciones. Barcelona: Paidós.

Barrios, C. (2014): Imagen acto y actos de imagen en la lectura de la representación fotográfica. XVIII Jornadas Nacionales de Investigadores en Comunicación.

Barthes, R. (1999): La cámara lúcida: Nota sobre la fotografía. Barcelona: Paidós.

Benjamin, W. (1989): Discursos Interrumpidos I. Buenos Aires: Taurus.

Butler, J. (2017): El género en disputa. Madrid: Paidós.

Fernández, A. (2012): Usos performativos de las imágenes. Re-visiones (12)2.

Fischer, E. (2011): Estética de lo performativo. Madrid: Abada Editores

Fontcuberta, J. (2016): La cámara de pandora. La fotografi@ después de la fotografia (2 ${ }^{\circ}$ ed.). Barcelona: Gustavo Gili

Fontcuberta, J. (2016b): La furia de las imágenes. Notas sobre la postfotografía. Barcelona: Galaxia Gutemberg 
Foucault, M., Varela, J., Álvarez-Uría, F., \& Álvarez-Uría, F. (2006). Historia de la sexualidad. Madrid: Siglo Veintiuno

Foucault, M. (2008): Tecnologías del yo y otros textos afines. Barcelona:Paidós

Green, D. y Lowry, J. (2007). "De lo presencial a lo performativo: nueva revisión de la indicialidad fotográfica”, en ¿Qué ha sido de la fotografía?. Barcelona: Gustavo Gili.

De Lauretis, T. (1989): Technologies of Gender. Essays on Theory, Film and

Fiction. London: Macmillian Press

Del Pozo, D. Romaní, M. y Villaplana, V. (2012): Abecedario Anagramático. Subtramas. http://subtramas.museoreinasofia.es/es

Prada, J.M. (2018): El ver y las imágenes en el tiempo de internet. Madrid: Akal.

Ribalta, J., \& Zelich, C. (2018). El espacio público de la fotografía : Ensayos y entrevistas. Barcelona: Ayuntamiento de Barcelona y Arcadia.

Zorita, M. (2013). El fotógrafo que murió dos veces. Albedomedia. https://www.albedomedia.com/cultura/historiografia/el-fotografo-que-murio-dos-veces/ 